\title{
Study of effects of Sudarshan Kriya on Postmenopausal symptoms among women from central India: A preliminary study
}

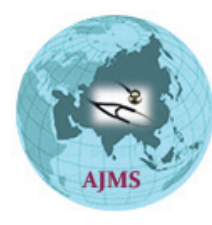

\author{
Rajeshree Tukaram Patil'1, Renuka Vivekanand Patil ${ }^{2}$, Suresh Narayanrao Ughade ${ }^{3}$, \\ Manjusha Sureshchandra Hatwar ${ }^{4}$
}

\begin{abstract}
${ }^{1}$ Associate Professor, Department of Obstetrics and Gynaecology, Government Medical College, Gondia, Maharashtra, India, ${ }^{2}$ Research Assistant, Indira Gandhi Government Medical College and Hospital, Nagpur, India, ${ }^{3}$ Biostatistician, Associate Professor, Department of Community Medicine, Government Medical College, Nagpur, ${ }^{4}$ Health Care Management, CARE Hospital, Dhantoli, Nagpur
\end{abstract}

Background: Menopausal health concerns mainly include the vasomotor symptoms, cardiovascular symptoms, osteoporosis, cancer, sexual problems and urogenital atrophy. Our life style today leads to a lot of stress, depression and anxiety. Prolonged stress can make one experience the symptoms like menopause (though not actually inducing it).Yoga exercise meditation and life style modification have relieved stress and enhanced the quality of life. Sudarshan Kriya (SK) is a rhythmic breathing technique with 4 breath components. It has varied effects on body especially acting by relief of stress. Aims and Objective: Assess the effects of SK on the commonly perceived symptoms experienced by the postmenopausal women in central India. Materials and Methods: A random sample of 156 women was interviewed by administering a pre-designed and pre-tested questionnaire. Questionnaire included 14 frequently occurring symptoms. Stress was scored on Likerts scale to assess the severity. (Score total = lowest 0 and highest 42 ). Those women doing regular SK for at least more than 1 year before the final menstrual period $(n=79)$ formed the Study group and women doing SK for less than 1 year, women following other health practices, or not following any health practice at all $(n=77)$ belonged to the Control group. Results: Women doing SK were found to be happier and content as compared to controls. SK with vegetarian diet was found effective in lowering the scores. Combining SK with exercises and yoga together can reduce the score to the lowest level. Minimum two years of regular practice was found enough to yield low scores and best quality of menopausal transformation. Conclusion: Initiating SK into the lives of postmenopausal women at the right time can assure a less morbid, more comfortable and a better quality of postmenopausal life.

Key words: Post-Menopausal symptoms, Sudarshan Kriya, Exercise, Yoga, Menstruation
http://nepjol.info/index.php/AJMS DOI: 10.3126/ajms.v8i5.17723 E-ISSN: 2091-0576 P-ISSN: $2467-9100$

\section{INTRODUCTION}

Menopause is a permanent cessation of menstruation resulting from loss of ovarian follicular activity. ${ }^{1} \mathrm{~A}$ natural menopause is said to have occurred after 12 months of amenorrhoea from the Final Menstrual Period (FMP). It occurs between 45 to 55 yrs age, with some variations between developed and developing countries.
Although the major consequences in menopause are related to estrogen deficiency or unopposed estrogens, but the principal health concerns are VMS (hot flushes, irritability, night sweats), CVS (shortness of breath and palpitations), osteoporosis (bone pain), cancer (cervix, uterus, vagina), sexual problems (libido, dyspareunia, vaginal dryness), urogenital atrophy.

For some women the symptoms of menopause are mild and pass off quickly while for others it is an explosion 
of symptoms like hot flushes, mood swings, irritability, insomnia etc.

Since the advent of hormone replacement therapy in 1960, up till now various treatment options have become available for management of menopausal symptoms. Now various complementary and alternative therapies are also being studied.

Rather, it has become more and more challenging to find a treatment which is more rewarding and less or non harmful at the same time. Stress depression and anxiety have become highly prevalent in the general population nowadays. Today's life style includes all those things which make us diverge too far from our natural homeostasis, thus leading to lot of stress. ${ }^{2}$ Stress actually means feeling under pressure both physically and emotionally. The way our body reacts to a particular situation also varies from person to person. For some it remains reasonably comfortable, while for others it can be a very stressful one.

\section{Study background}

To cope up with stress our body produces cortisol. Infact, estrogen regulates this cortisol levels. But, during menopause as estrogen decreases, the regulation of cortisol gets affected and stress is experienced more readily. Study conducted elsewhere indicates, that continuous high level of prolonged stress can make one experience symptoms resembling menopause, though not actually inducing it. ${ }^{3}$

Yoga, exercise, meditation, life style modification have been found to relieve stress and ease out the menopausal transition thereby enhancing the quality of life. ${ }^{4-10}$

Sudarshan Kriya (SK) is a rhythmic breathing technique. According to various studies, those who practice it daily have varied beneficial effects on their body in different aspects, especially in relieving stress. ${ }^{11-15}$

Research shows that SK increases beta and alpha activity in brain. Beta activity is known to improve alertness while increased alpha activity gives relaxation. Thus, together SK gives a state of restful alertness. ${ }^{12}$

Thus SK can take one out of stress and provide a relaxed and stress free life. SK also acts by reducing blood lactate levels. Blood lactate is an indicator of stress. Reduced blood lactate levels indicate stress reduction. SK also increases glutathione and superoxide dismutase (SOD) levels in the blood. ${ }^{15}$ Glutathione and superoxide dismutase are antioxidant enzymes that delay aging, hence can have an important effect in postmenopausal women.
A SK package as taught in various Happiness Programs of the Art of Living, mainly includes 4 breath components: Normal, Ujjayi, Bhastrika and Normal breath in 3 rhythms.

It is advisable to do a few light stretching exercises and yogasanas prior to following the SK package, so as to get a complete benefit of SK. Regular practitioners of SK describe feeling peaceful, clear minded, happy, focussed and connected together. Many people show immediate effects with improvement in mood and anxiety. There is also improvement in lung and cardiac endurance, improved circulation, antioxidants and immunity levels. SK also increases natural killer cells and protects from cancer to a large extent. Cancer is a major concern in and after menopause. Largely it has no contraindications, side effects or risk of addictions. The current study was designed with an objective of establishing the effects of Sudarshan Kriya on commonly perceived symptoms experienced by the postmenopausal women.

\section{MATERIALS AND METHODS}

The current study was conducted in 5 districts of Vidarbha namely, Akola, Amravati, Wardha, Yavatmal, Nagpur. This was a cross sectional survey and the duration of the study was from January 2016 to May 2016.

\section{Setting}

Art of living follow up centres, yoga centres, parks, street walkers, public places.

\section{Study group}

Postmenopausal women doing SK regularly for at least one year before attaining menopause.

\section{Controls}

Postmenopausal women doing SK for less than one year and postmenopausal women using or not using any other health practices.

\section{Sample size}

A sample size of 144 was considered as sufficient to detect as low as $40 \%$ of the proportion of women with postmenopausal symptoms with $95 \%$ confidence level \& $20 \%$ precision (prevalence is subjective and variable from 36 to $81 \%)$.

\section{Inclusion criteria}

Women between 45 to $55 \mathrm{yrs}$ of age, who did not have menses for at least one year before the final menstrual period (FMP).

Study group included women only if they were doing regular SK for at least more than one year before the final 
menstrual period. All other women were in control group. Any other health practices followed by the women in both study and control group were identified (eg. Yoga, walking, exercise, music, meditation) and the duration noted. Thus women doing SK for less than one year or following other health practices or not following any practice at all were included in controls. Lastly, only those women who showed their willingness to participate were included in the study.

Data collection

The questionnaire prepared included socio-demographic features BMI, menstrual, family history obstetrical historyand 14 frequently occuring postmenopausal symptoms.

\section{Analysis}

Descriptive statistics like mean, Standard deviation, percentage, frequency were calculated for continuous or categorised variables respectively.

The differences in the mean in between the 2 groups were assessed by unpaired or independent sample t test, while differences in proportions were evaluated by chi square test, $\mathrm{p}$ value.

\section{Results}

A random sample of 156 postmenopausal women fulfilling the inclusion criteria was collected and separated as Controls $(n=77)$, Study $(n=79)$. Overall the women practicing SK were happy and content.

Table 1 shows, the comparison of the socio-demographic characteristics.

Women in both the groups were found to match in sociodemographic characters and family type.
Table 2 shows comparison of dietary pattern among study and control group subjects. Vegeterian diet with SK reduced the scores in the study.

Table 3 shows, the effects of Sudarshan Kriya on menstrual flow during the menopausal transition. The women in control group had heavy flow as compared to the study group.

Table 4 shows, the Kriya duration. Study group included women who did SK for at least one year before the FMP and continued regularly thereafter. The duration of doing regular SK (total) was divided arbitrarily to get the mean scores. In study group, most $(n=44)$ of the women had been doing SK for only one to two years before the FMP. Regular SK for 1 to 2 years is sufficient to have the best effects in scores.

Table 5 shows the postmenopausal symptoms. Many women in controls experienced severe symptoms $(\mathrm{p}=0.00)$. only few women in study had total scores beyond 15 .

Table 6 shows, the comparison between SK and other health practices. The women doing SK exclusively had low scores $(7.2 \pm 4.02)$ giving statistically significant values in contrast to those in controls $(20.14 \pm 8.86)$ who did not follow any health practice at all.

It was also found that in study group a combination of SK with other health practices proved beneficial as the previously low scores were lowered down further.

\section{DISCUSSION}

Although there is no evidence to validate that stress causes early menopause, but according to Chris Iliades, stress can

\section{Table 1: Socio-demographic features}

\begin{tabular}{lcccc}
\hline Characteristics & Mean control & Mean study & Standard deviation control & Standard deviation study \\
\hline Age & 50.5 & 50.6 & 4.0 & 0.7 \\
Height & 5.0 & 5.6 & 11.8 & 3.6 \\
Weight & 60.5 & 60.6 & 4.8 & 10.6 \\
BMl & 23.6 & 22.8 & 4.2 \\
Family type & 52 & 49 & \\
\hline
\end{tabular}

Table 2: Comparison of QOL scores in two groups by dietary patterns of women

\begin{tabular}{|c|c|c|c|c|}
\hline \multirow[t]{2}{*}{ Diet pattern } & \multicolumn{2}{|c|}{ Study group $(n=79)$} & \multicolumn{2}{|c|}{ Control group $(n=77)$} \\
\hline & $\mathbf{N}(\%)$ & Mean $\pm S D$ scores & $\mathbf{N}(\%)$ & Mean $\pm S D$ scores \\
\hline Veg & 75 (94.93) & $6.4^{\star *} \pm 4.1$ & $52(67.53)$ & $17.4 \pm 9.8$ \\
\hline Non-veg & $1(1.26)$ & - & $21(27.27)$ & $17.2 \pm 6.6$ \\
\hline Fast food & $2(2.52)$ & $8.5 \pm 6.4$ & - & - \\
\hline Veg \& non-Veg & - & - & $1(1.3)$ & - \\
\hline Non-veg \& fast food & $1(1.26)$ & - & $2(2.6)$ & $18.0 \pm 9.9$ \\
\hline Veg, non-veg \& fast food & - & - & $1(1.26)$ & - \\
\hline
\end{tabular}


Table 3: Menstrual flow in women in menopausal transition in two groups

\begin{tabular}{|c|c|c|c|c|c|}
\hline \multirow[t]{2}{*}{ Flow } & \multicolumn{2}{|c|}{ Study group ( $n=79)$} & \multicolumn{2}{|c|}{ Control group $(n=77)$} & \multirow[t]{2}{*}{$p$ value } \\
\hline & $\mathbf{N}(\%)$ & Mean $\pm S D$ & $N(\%)$ & Mean $\pm S D$ & \\
\hline Average flow & $14(17.72)$ & $5.75 \pm 3.98$ & $9(11.40)$ & $14.66 \pm 8.09$ & 0.0019 \\
\hline Heavy flow & $5(6.33)$ & $3.0 \pm 1.87$ & $19(20.05)$ & $20.0 \pm 6.51$ & 0.0001 \\
\hline
\end{tabular}

Table 4: Effect of Kriya duration on QOL scores of women in two groups

\begin{tabular}{lcc} 
Kriya duration & \multicolumn{2}{c}{ Study group $(\mathbf{n = 7 9 )}$} \\
\cline { 2 - 3 } & $\mathbf{N}(\%)$ & Mean $(\mathbf{\pm S D})$ scores \\
\hline $1-2$ years & $44(55.7)$ & $5.7 \pm 3.7$ \\
$2.1-5$ years & $12(18.2)$ & $8 \pm 3.7$ \\
$5.1-0$ years & $20(25.3)$ & $6.8 \pm 4.7$ \\
$>10$ years & $3(3.8)$ & $6.3 \pm 5.0$ \\
\hline $\mathrm{p}=0.0001$ & &
\end{tabular}

Table 5: Postmenopausal symptoms in women in two groups

\begin{tabular}{|c|c|c|c|c|c|c|}
\hline \multirow[t]{2}{*}{ Symptoms } & \multirow[t]{2}{*}{ Groups } & \multicolumn{4}{|c|}{$\mathbf{N}(\%)$} & \multirow[t]{2}{*}{$\mathbf{p}$} \\
\hline & & 0 & 1 & 2 & 3 & \\
\hline \multirow[t]{2}{*}{ Hot flushes } & Control & $25(32.5)$ & 12 (15.6) & 12 (15.6) & $28(36.3)$ & 0.01 \\
\hline & Study & $44(55.7)$ & 12 (15.2) & 7 (8.9) & $4(5.1)$ & \\
\hline \multirow[t]{2}{*}{ Night sweats } & Control & $30(39.0)$ & $6(7.8)$ & 12 (15.6) & $29(37.6)$ & 0.01 \\
\hline & Study & $43(54.4)$ & $25(31.6)$ & 10 (12.6) & $1(1.3)$ & \\
\hline \multirow[t]{2}{*}{ Mood swings } & Control & $23(29.8)$ & $18(23.4)$ & $18(23.4)$ & $18(23.4)$ & 0.01 \\
\hline & Study & $46(58.2)$ & $28(35.4)$ & $4(5.1)$ & $1(1.3)$ & \\
\hline \multirow[t]{2}{*}{ Libido } & Control & 32 (41.5) & $24(31.2)$ & 12 (15.6) & $9(11.7)$ & 0.01 \\
\hline & Study & 56 (79.9) & $20(25.3)$ & $3(3.8)$ & $0(0.00)$ & \\
\hline \multirow[t]{2}{*}{ Fatigue } & Control & $21(27.3)$ & $21(27.3)$ & $18(23.4)$ & $17(22.1)$ & 0.01 \\
\hline & study & 42 (53.2) & $29(36.7)$ & 7 (8.8) & $1(1.3)$ & \\
\hline \multirow[t]{2}{*}{ Sleep disturbance } & Control & $29(37.7)$ & $17(22.1)$ & $17(22.1)$ & $14(18.2)$ & 0.01 \\
\hline & Study & 56 (79.9) & $17(21.5)$ & $5(6.3)$ & $1(1.3)$ & \\
\hline \multirow[t]{2}{*}{ Headache } & Control & $35(45.4)$ & $26(33.8)$ & $8(10.4)$ & $8(10.4)$ & 0.01 \\
\hline & Study & 56 (79.9) & $19(24.0)$ & $4(5.1)$ & $0(0.0)$ & \\
\hline Bloating & Study & $50(63.3)$ & $25(31.6)$ & $2(2.5)$ & $2(2.5)$ & \\
\hline \multirow[t]{2}{*}{ Weight gain } & Control & $35(45.4)$ & $14(18.2)$ & 15 (19.5) & 13 (16.9) & 0.01 \\
\hline & Study & $42(53.2)$ & $28(35.4)$ & 7 (8.9) & $2(2.5)$ & \\
\hline \multirow[t]{2}{*}{ Joint stiffness } & Control & $17(22.1)$ & 15 (19.5) & $28(36.4)$ & $17(22.1)$ & 0.01 \\
\hline & Study & 41 (51.9) & $24(30.4)$ & 12 (15.2) & $2(2.5)$ & \\
\hline \multirow[t]{2}{*}{ Hair loss } & Control & $20(26.0)$ & $22(28.6)$ & $22(28.6)$ & $10(13.0)$ & 0.01 \\
\hline & Study & $38(48.1)$ & $31(39.2)$ & $5(6.3)$ & $5(6.3)$ & \\
\hline \multirow[t]{2}{*}{ Depression } & Control & $30(39.0)$ & $12(15.6)$ & $25(32.5)$ & $10(13.0)$ & 0.01 \\
\hline & Study & $63(79.7)$ & $14(17.7)$ & $2(2.5)$ & $0(0.0)$ & \\
\hline \multirow[t]{2}{*}{ Anxiety } & Control & $28(36.4)$ & $16(20.8)$ & $18(23.4)$ & 15 (19.5) & 0.01 \\
\hline & Study & $57(72.1)$ & $21(26.6)$ & $1(1.3)$ & $0(0.0)$ & \\
\hline \multirow[t]{2}{*}{ Loss of concentration } & Control & $29(37.7)$ & $16(20.8)$ & $24(31.2)$ & $8(1.5)$ & 0.01 \\
\hline & Study & $64(81.0)$ & $13(16.4)$ & $2(2.5)$ & $0(0.0)$ & \\
\hline
\end{tabular}

make one experience the symptoms of menopause more severely. ${ }^{3}$

As SK acts to relieve stress, ${ }^{11,12,15}$ similarly the women doing SK regularly had experienced postmenopausal symptoms less severely. Physicians committee for responsible medicine (PCRM) had found that women taking high fat low fibre diet have high estrogens so they experience a dramatic fall of estrogens during menopause making the postmenopausal symptoms more severely felt. ${ }^{16}$
Asian women on the contrary take less fat more fibre diet. They have a less dramatic fall in estrogens and hence experience milder forms of postmenopausal symptoms. Even Mayan (Mayans are a group of people of Mesoamerica, who inhabit southern Mexico) women taking similar diet (as Asians) in South East Mexico have not experienced hot flushes at all.

So low fat vegetarian diet is strong recommendation for those who experience hot flushes. ${ }^{16,17}$ In present study, vegetarian diet with SK could reduce the severity of 


\begin{tabular}{|c|c|c|c|c|c|}
\hline \multirow[t]{2}{*}{ Health practices comparison } & \multicolumn{2}{|c|}{ Study group ( $n=79$ ) } & \multicolumn{2}{|c|}{ Control group $(n=77)$} & \multirow[t]{2}{*}{ p } \\
\hline & $\mathbf{N}(\%)$ & Mean $\pm S D$ & $\mathbf{N}(\%)$ & Mean $\pm S D$ & \\
\hline Kriya+Yoga in study group versus only yoga in control group & $36(45.6)$ & $7.2 \pm 4.01$ & $17(22.1)$ & $16 \pm 8.2$ & 0.0001 \\
\hline Kriya+Exercise in study group versus only exercise in control group & $22(27.8)$ & $4.7 \pm 5.2$ & $11(14.3)$ & $16 \pm 5.3$ & 0.0001 \\
\hline $\begin{array}{l}\text { Kriya+Yoga+Exercise in study group versus Yoga+Exercise in control } \\
\text { group }\end{array}$ & $14(17.7)$ & $4.3 \pm 3.9$ & $4(5.1)$ & $7.5 \pm 9.4$ & 0.3096 \\
\hline
\end{tabular}

postmenopausal symptoms to a statistically significantly low level. Thus, low fat high fibre vegetarian diet with SK can be a recommendation for hot flushes.

Bleeding is one of the troublesome symptoms closer to menopause. It can also be an indication for a major surgery like hysterectomy, if it goes beyond control, thereby creating other complications. The finding of reduction in blood flow in the present study, is an important effect which can help a peri-menopausal women to attain a smooth menopause, provided her duration for SK is sufficiently longer before attaining menopause. Although, study on larger number of women is necessary to assure that $\mathrm{SK}$ reduces the blood flow and also maintains regular menstrual cycles.

Two frequently occurring symptoms like weight gain and loss of muscle strength can be staved off in an excellent way by regular exercise. ${ }^{4-7}$ Women doing regular SK can maintain weight gain and prevent loss of muscle strength as is seen in the table 5 of symptoms.

During menopause cortisol regulation is affected and oestrogen levels fall. Both together take the toll on the heart leading to increased risk of heart disease during menopausal transition. According to centre disease control (CDC), Aerobic activity for menopausal women is good for cardiac. An aerobic exercise is the activity which increases and sustains the heart rate for 15 to $30 \mathrm{~min}$. CDC recommends 150 min of moderate aerobic activity or $75 \mathrm{~min}$ of vigorous aerobic activity a week. Regular aerobic exercise or equivalent physical activity is strongly recommended for women with hot flushes. ${ }^{10}$ In the present study, only 13\% women doing regular SK had moderate to severe hot flushes, while $51.94 \%$ women in controls had experienced moderate to severe form of hot flushes. This suggests that SK alone can improve the physiological status equivalent to aerobic exercise. Furthermore SK package as already suggested (but not mandatory) if preferably done with a few stretches and yogasanas before doing SK can benefit significantly by maintaining muscle strength and reducing the severity of hot flushes. Women doing regular SK also feel more energetic and efficacious in work. This aspect needs to be studied further with respect to effect on cardiovascular system.
CDC also recommends 7 to $8 \mathrm{hrs}$ of sleep, deep breathing exercises and relaxation technique and meditation. SK is a breathing exercise that improves sleep gives relaxation and brings a calm peaceful state of mind in post Kriya phase.

As already stated from literature, yoga, exercise, meditation and lifestyle modification relieve stress ease out menopausal transition and enhance the quality of life.

The present study observed that exercise along with yoga and SK can be recommended as a wholesome treatment for frequently occurring postmenopausal symptoms. Thus it seems a most rewarding, non-harmful least expansive alternative to alleviate post menopausal symptoms.

\section{CONCLUSIONS}

Women doing regular SK were more happy and content. High fibre vegetarian diet can be recommended with SK to alleviate hot flushes. Light stretching exercises and yogasanas done prior to SK can also be helpful to bring the Likert score to lower side. Thus the postmenopausal sufferings can now be felt only negligibly provided this practice is followed regularly. A minimum of just 1 to 2 years of regular practice of SK can give the best quality of menopausal transition w.r.t severity of experiencing the postmenopausal symptoms. Initiating SK into the lives of postmenopausal women at the right time can assure a less morbid, more comfortable and a better quality of postmenopausal life.

\section{ACKNOWLEDGEMENTS}

Special thanks to Mrs. Ranjana Channe for tabulating the data and helping ease out calculations, graphs and corrections.

\section{REFERENCES}

1. www.imsociety.org/menopause_terminology.php

2. https://en.wikipedia.org/wiki/Stress, anxiety,depression

3. 'The link between stress and early menopause", Chris lliads,MD,

4. Kjellgren A, Bood SA, Axelsson K, Norlander T and Saatcioglu F. Wellness through a comprehensive yogic breathing program-a 
controlled pilot trial. BMC Complementary and Alternative medicine 2007; 7:43.

5. Brown RP and Gerabarg PL. Sudarshan Kriya Yogic breathing in the treatment of stress, anxiety and depression: part II-clinical applications and guidelines. The Journal of Alternative and Complimentary medicine 2005; 11: 711-717.

6. Brown RP and Gerabarg PL. Sudarshan Kriya Yogic breathing in the treatment of stress, anxiety and depression: part I- neuro physiologic model. The Journal of Alternative and Complimentary medicine 2005; 11: 189-201.

7. Geetha H, Chitra H, Kubera NS and Pranthi M. Quality of life after menopause: Effects of hormone replacement therapy, vitamin $\mathrm{E}$, and sudarshan kriya yoga practice. A comparative study. Biomedical Research 2014; 25(2):240-242.

8. Vaze $\mathrm{N}$ and Joshi $\mathrm{S}$. Yoga and menopausal transition. J midlife health 2010; 1(2):56-58.

9. Desai $R$, Tailor A and Bhatt T. Effects of yoga on brain waves and structural activation: A review. Department of Physical Therapy, University of Illinos at Chicago, Chicago,USA, Complimentary Therapies in Clinical Practice 2015; 21: 112-118.

10 www.healthline.com > Menopause > Lifestyle

11. Chandra S, Sharma G, Mittal AP, and Jha D. Effect of Sudarshan Kriya (meditation) on gamma, alpha, and theta rhythm during working memory task. Int J Yoga 2016; 9(1): 72-76.

12. Bhatia M, Kumar A, Kumar N, Pandey RM, Kochipillai V and Singh N. Electrophysiological evaluation of Sudarshan Kriya: an EEG, BAER and P300 study. Ind J Physiol Pharmacol 2003; 47: $157-163$

13. Travis F, Hagga DH, Hagelin JS, Tanner M, Arenander A, Nidich S, et al. A self Referential Default Brain State: Patterns of Coherence, Power and e LORETA sources during Eyes Closed Rest and Transcendental Meditation Practice. Cognitive Processes 2010; (1):21-30.

14. Fox KCR, Savannah N, Mathew DL, Floman JL, Ellamail M, Kalina $C$, et al. Is meditation associated with altered brain structure? A systematic review and metaanalysis of morphometric neuroimaging in mediation practitioners. Neurosci Bio Behav Rev 2014; 43:48-73.

15. Sharma H, Sen S, Singh A, Bhardwaj NK, Kochipillai V and Singh N. Sudarshan Kriya practitioners exhibit better antioxidant status and lower blood lactate levels. Biol Psychol 2003; 63:284-291.

16. www.pcrm.org/health/health topics/A Natural Approach to Menopause.

17. www.women to women.com/women-perimenopausal/5 steps for natural menopause relief/2.

\section{Author's contribution:}

RTP - Concept of the research, Study design, Data acquisition, Interpretation and Analysis, Final approval of the publication; RVP - Study design, Study settings, Data collection, Critical approval; SNU - Statistical analysis of the data. critical appraisal of interpretation and final approval; MSH-Idea of the study, study settings, data collection

\section{Orcid ID:}

Dr. Rajeshree Patil: (i) http://orcid.org/0000-0002-7619-242X

Dr. Renuka Vivekanand Patil: (i) http://orcid.org/0000-0002-2903-084X

Ms. Manjusha Sureshchandra Hatwar: (1) http://orcid.org/0000-0001-7598-0734

Source of funding: Nil, Conflict of interest: None. 